\title{
Research of structural entropy of sheet aluminium alloys depending on annealing temperature
}

\author{
Ekaterina Nosova ${ }^{1, *}$, Fedor Grechnikov ${ }^{2}$, and Natalia Lukonina ${ }^{1}$ \\ ${ }^{1}$ Samara University, Metal Technology and Aviation Material Science Department, 34, Moskovskoye \\ shosse, Samara, 443086, Russia, \\ ${ }^{2}$ Samara University, Metal Pressure Working, 34, Moskovskoye shosse, Samara, 443086, Russia
}

\begin{abstract}
Sheet blanks' structure uniformity determines their ability to sheet stamping. Level of entropy may represent the characteristic of structural uniformity. Structural entropy was received from strain curves recalculation for sheet blanks from aluminium alloys $\mathrm{Al}-2 \mathrm{Mg}$ and $\mathrm{Al}-6 \mathrm{Mg}$ are presented in the work. Stain curves were provided for blanks after cold deformation and annealing at temperatures 250,350 и $450^{\circ} \mathrm{C}$. Estimation of grain size uniformity was made. Effect of annealing temperature on structural entropy and grain structure uniformity was found. It was shown that annealing temperature increasing leads to structural entropy decreasing. Ununiformity of grain size achieves the minimal values after annealing at temperature $350^{\circ} \mathrm{C}$ for both alloys, and then ununiformity grows after annealing at temperature $450^{\circ} \mathrm{C}$.
\end{abstract}

\section{Introduction}

High-entropy alloys present a new grade of materials, which are based on several components presence in equimolar composition or close to equimolar proportion [1-2].

These alloys may be used as individual structural materials, as described in papers [3-4], or as reinforcement components and covers [5-7]. Results presented in works [8-9] shows increasing in hardness, strength, corrosion resistance of covered materials and composites.

Configure entropy is offered to calculate using next formulae [10]:

$$
\Delta S_{\text {conf }}=-R \sum_{i=1}^{n} X_{i} \times \ln X_{i}
$$

where $\mathrm{n}$ - number of components, $\mathrm{Xi}$ - i-component' molar portion, $\mathrm{R}=8.314 \mathrm{~J} / \mathrm{mol}^{*} \mathrm{~K}-$ the ideal gas constant.

For alloys which elements are presented in equal molar concentration (equimolar) this formulae can be simplified as follow [10]:

* Corresponding author: eanosova@mail.ru 


$$
\Delta S_{\text {conf }}=R \times \ln (n)
$$

In accordance to classification presented in work [11] alloys may be divided on entropy level as follows: low entropy (LEA), middle entropy (MEA) and high entropy (HEA). It is proposed to consider alloy as high entropy if $\Delta \mathrm{Sconf} \geq 1.5 \mathrm{R}$. When $1.0 \mathrm{R} \leq \Delta \mathrm{Sconf} \leq 1.5 \mathrm{R}$, alloys are considered as middle entropy. In the case $\Delta \mathrm{Sconf} \leq 1.0 \mathrm{R}$ alloys could be considered as low entropy.

However structure and consequently structural (or configure) entropy can change during treatment, for example working or heat treatment [12-13].

Change in structural entropy can be estimated via the measurement of energy absorbed or scattered material in the process of structural transformation. N.G.Kolbasnikov has proposed the approach to estimate structural entropy changing based on stress-strain curves received after standard uniaxial tensile test [14].

This paper shows the results of stress-strain curves recalculation for sheet blanks of aluminium alloys $\mathrm{Al}-2 \mathrm{Mg}$ and $\mathrm{Al}-6 \mathrm{Mg}$ after cold working and recrystallization annealing. Also interrelation between indexed alloys' grain structure change and structural entropy was demonstrated. The structural entropy calculation technique from stress-strain curves is shown in details.

\section{Materials and methods}

Sheet blanks of aluminium alloys $\mathrm{Al}-2 \mathrm{Mg}$ and $\mathrm{Al}-6 \mathrm{Mg}$ (containing 2 and 6 mass\% of $\mathrm{Mg}$ respectively) were used as initial materials. Thickness of Al-2Mg blanks was about $1.5 \mathrm{~mm}$, of Al-6Mg $-2.0 \mathrm{~mm}$ ). Blanks were annealed at temperature $480^{\circ} \mathrm{C}$ and cold rolled with thickness reducing $20 \%$. Then pieces were annealed at temperatures $250,350,450^{\circ} \mathrm{C}$ during 30 minutes.

Standard uniaxial tensile test was made for calculation of structural entropy changing.

Technique of structural entropy calculation via stress strain curves was follow.

In accordance to positions presented in monograph [14], structural entropy may be calculated using formulae:

$$
\Delta S_{c m p}=-R \int_{\sigma=0}^{\sigma=\sigma_{\max }} f\left(\sigma^{*}\right) \times \ln f\left(\sigma^{*}\right) d \sigma^{*}
$$

where $f\left(\sigma^{*}\right)$-of the dimensionless yield strength probability density. The dimensionless value of stress should be calculated as $\sigma^{*}=\sigma / \mathrm{E}$, where $\sigma$ - stress values having dimension (MPa), E - Young modulus (MPa).

Technique of stress-strain curves analysis of samples having different defects (deformation, annealing, quenching etc.) density is proposed for receiving $f\left(\sigma^{*}\right)$ in indexed monograph. After uniaxial tensile test the approximate function must be choose with the maximum correlation index for stress-strain curve.

For example, uniaxial tensile test was worked out for sample form Al-6Mg alloy after cold rolling and annealing at temperature $250^{\circ} \mathrm{C}$ during 30 minutes, stress-strain curve for this test is represented on fig 1 .

decreasing of the tensile strength. 


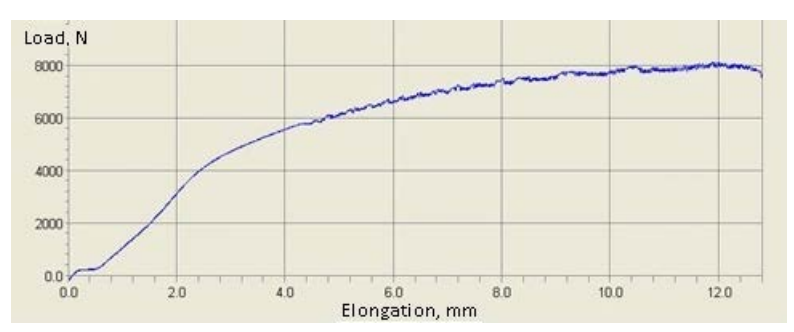

Fig. 1. Experimental stress-strain curve for cold rolled and annealed at $250^{\circ} \mathrm{C}$ during 30 minutes $\mathrm{Al}-$ $6 \mathrm{Mg}$ alloy sample after uniaxial tensile test

Approximate function $\sigma=170,68+16,703^{*} \varepsilon-0,1785 \varepsilon 2$ with correlation index $\mathrm{R} 2=0.9988 \mathrm{was}$ found for received experimental curve (type of function is $\sigma=$ $\sigma \mathrm{T} 0+\alpha 1 * \varepsilon+\alpha 2 * \varepsilon 2$ ). This function had the maximum value of the correlation index. Chart of experimental dots and approximate function, chosen using Microsoft Excell Software is shown on fig. 2 .

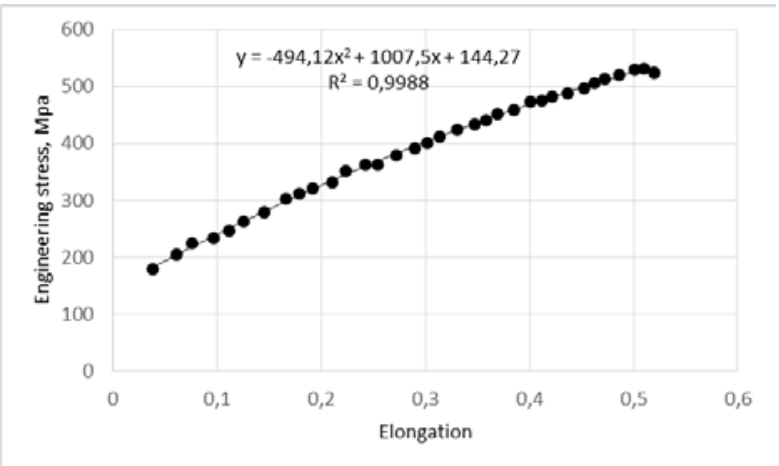

Fig. 2. Approximate dependence for experimental data received after tensile test of Al-6Mg alloy sample pass cold deformation and annealing at temperature $250^{\circ} \mathrm{C}$ during 30 minutes

Change of structural entropy $\Delta \operatorname{Sc}$ тр may be determined from dependence:

$$
f\left(\sigma^{*}\right)=-\frac{h+1}{E} \times \frac{d^{2} \sigma}{d \varepsilon^{2}}
$$

First and second derivative of function $\sigma=\sigma_{\mathrm{T} 0}+\alpha_{1} * \varepsilon+\alpha_{2} * \varepsilon^{2}$, presented on fig.2 will be follow $\left(\sigma=144,7+1007,5^{*} \varepsilon-424,12^{*} \varepsilon_{2}\right)$ :

First derivative $\frac{d \sigma}{d \varepsilon}=\alpha_{1}+2 * \alpha_{2} * \varepsilon=1007,5-2 * 494,12 * \varepsilon$

Young modulus $\mathrm{E}$ can be found when the argument of the first derivative tends to 0 $(\varepsilon \rightarrow 0): E=\alpha_{1}=1007,5$

Index $h$ can be found from the first derivative when $\varepsilon \rightarrow \infty: \frac{d \sigma}{d \varepsilon}=\frac{h \times E}{1+h}$ 
$h=\frac{E-\frac{d \sigma}{d \varepsilon}}{\frac{d \sigma}{d \varepsilon}}$. During test maximum elongation (deformation) become $\varepsilon=0,519399$, therefore $\frac{d \sigma}{d \varepsilon}=\alpha_{1}+2 * \alpha_{2} * \varepsilon=1007,5-2 * 494,12 * 0.519399=494,2$ From above $h=\frac{E-\frac{d \sigma}{d \varepsilon}}{\frac{d \sigma}{d \varepsilon}}=\frac{1007,5-494,2}{494,2}=1,039$

$$
\frac{d^{2} \sigma}{d \varepsilon^{2}}=2 * \alpha_{2}=-2 * 494,12=-988,24
$$

Then $f\left(\sigma^{*}\right)=-\frac{h+1}{E} \times \frac{d^{2} \sigma}{d \varepsilon^{2}}=-\frac{1,039+1}{1007,5} \times(-988,24)=2$ is

It means that $\mathrm{f}\left(\sigma^{*}\right)$ is a constant, not depending on $\varepsilon$. Then structural entropy changing

$$
\begin{aligned}
& \Delta S_{c m p}=-R \int_{\sigma=0}^{\sigma=\sigma_{\max }} f\left(\sigma^{*}\right) \times \ln f\left(\sigma^{*}\right) d \sigma^{*}=-8,31 \int_{179.0}^{524.6} 2 * \ln (2) d \sigma^{*}= \\
& \ln (2) \frac{1}{1007_{a} 5} \int_{179_{0} 0}^{524.6} d \sigma * 8.31 * 2 *
\end{aligned}
$$

Using this technique the structural entropy change was calculated for the rest of samples.

Grain size was determined in accordance to Russian Standard GOST 5639-82 Steels and alloys. Methods for the detection and determination of grain size (ASTM E112 - 13). Grain size uniformity was determined using FREQUENCY option of Microsoft Excell Software from sample of grain size consisting of $10 \ldots 12$ values. The more uniform the grain size, the narrower the histogram of the distribution of grain size values. The width of the histogram was determined by calculating the standard deviation from the sample of the same grain size values as for the grain size. Ununiformity $\beta$ was quantity estimated as ratio of standard deviation $\mathrm{b}(\mathrm{mkm})$ to the most probable grain size dpos $(\mathrm{mkm})$ and histogram height $\mathrm{h}$ at the point with the greatest likelihood of grain size:

$$
\beta=\frac{b}{d_{p o s} \times h}
$$

The smaller this value, the more uniform the grain structure.

\section{Results and discussion}

The microstructure of $\mathrm{Al}-2 \mathrm{Mg}$ and $\mathrm{Al}-6 \mathrm{Mg}$ alloys after annealing at different temperatures is shown in Fig. 1. 

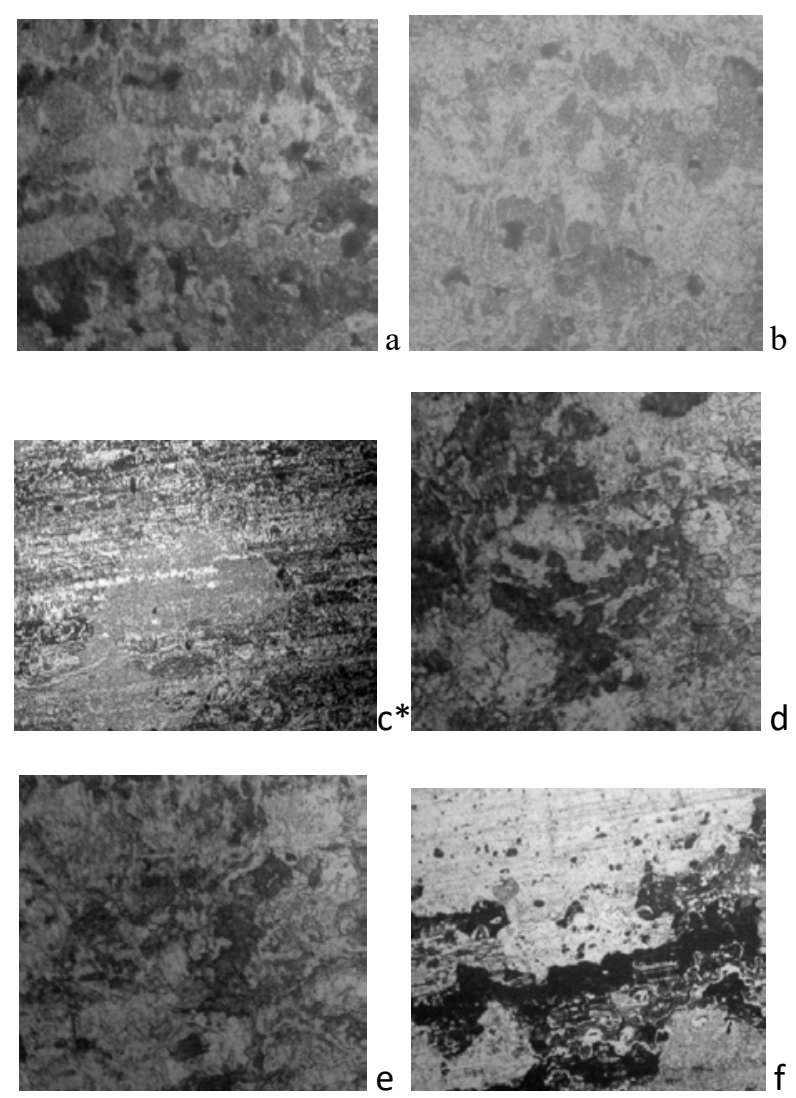

Fig. 3. Microstructure of samples from $\mathrm{Al}-2 \mathrm{Mg}(\mathrm{a}-\mathrm{c})$ and $\mathrm{Al}-6 \mathrm{Mg}(\mathrm{d}-\mathrm{e})$ alloys after annealing at temperature: $\mathrm{a}, \mathrm{d}-250^{\circ} \mathrm{C}, \mathrm{b}, \mathrm{e}-350^{\circ} \mathrm{C}, \mathrm{c}, \mathrm{f}-50^{\circ} \mathrm{C}, \mathrm{X} 100\left({ }^{*}\right.$ microstructure was made at X50)

From fig.3, grain size uniformity of alloys after annealing at temperature $350^{\circ} \mathrm{C}$ and pronounced ununiformity after annealing at temperature $450^{\circ} \mathrm{C}$.

Fig. 4 и 5 show charts of alloys $\mathrm{Al}-2 \mathrm{Mg}$ and $\mathrm{Al}-6 \mathrm{Mg}$ average grain size and grain ununiformity depending on annealing temperature.

From fig.4, the annealing temperature increasing leads to grain size monotonic growth in both alloys. Received data match with results published in [15].

Ununiformity does not have the monotonic behavior depending on annealing temperature (fig. 5). The most pronounced minimum grain size can be observed at the annealing temperature $350^{\circ} \mathrm{C}$ for $\mathrm{Al}-6 \mathrm{Mg}$. Alloy $\mathrm{Al}-2 \mathrm{Mg}$ has less observed grain size ununiformity dependence on annealing temperature. 


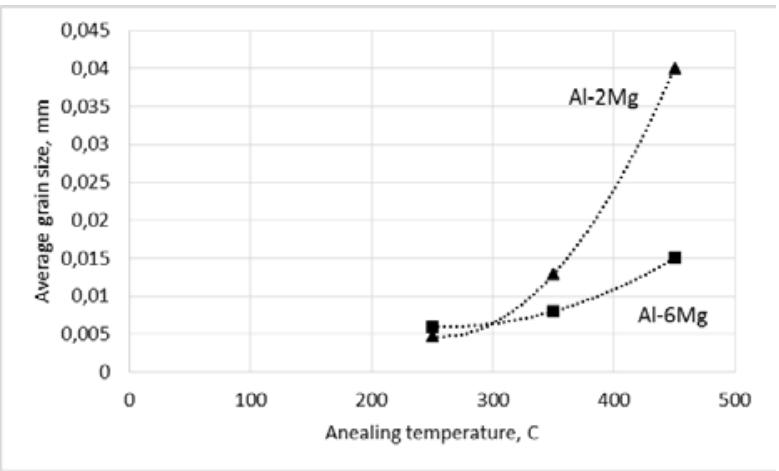

Fig. 4. Charts of average grain size in alloys $\mathrm{Al}-2 \mathrm{Mg}$ and $\mathrm{Al}-6 \mathrm{Mg}$ at different annealing temperature

Decreasing of grain size ununiformity after annealing at temperature $350^{\circ} \mathrm{C}$ can be explained by primary recrystallization finishing in both alloys, what leads to uniform equiaxial grain structure forming. Further temperature increasing can lead to collective recrystallization in the $\mathrm{Al}-6 \mathrm{Mg}$ alloy, i.e. the presence of a significant amount of magnesium can promote the growth of grain.

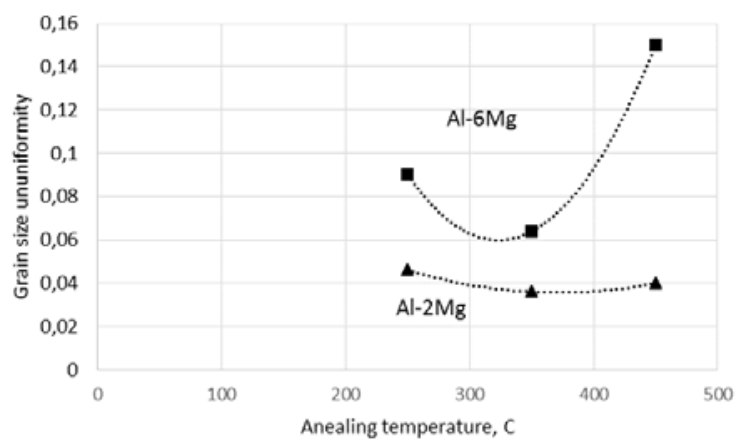

Fig. 5. Charts of grain size ununiformity in alloys $\mathrm{Al}-2 \mathrm{Mg}$ and $\mathrm{Al}-6 \mathrm{Mg}$ depending on annealing temperature

Configure entropy of alloys $\mathrm{Al}-2 \mathrm{Mg}$ and $\mathrm{Al}-6 \mathrm{Mg}$ calculated using formulae (1) has value of 0,998 и $2,15 \mathrm{~J} / \mathrm{mol}^{*} \mathrm{~K}$ respectively. While using classification features of alloys published in [11], these data corresponds to $0,12 \mathrm{R}$ и $0,26 \mathrm{R}$. It means that researched alloys are low-entropy one. Paper [10] shows calculation of Al-20Cu-10Mg triple alloy' configure entropy which is $5,55 \mathrm{~J} / \mathrm{mol}^{*} \mathrm{~K}$. This value is significantly higher than the values obtained for $\mathrm{Al}-2 \mathrm{Mg}$ and $\mathrm{Al}-6 \mathrm{Mg}$ alloys, as well as the content of alloying elements in the $\mathrm{Al}-20 \mathrm{Cu}-$ $10 \mathrm{Mg}$ alloy compared to those considered in this study. 


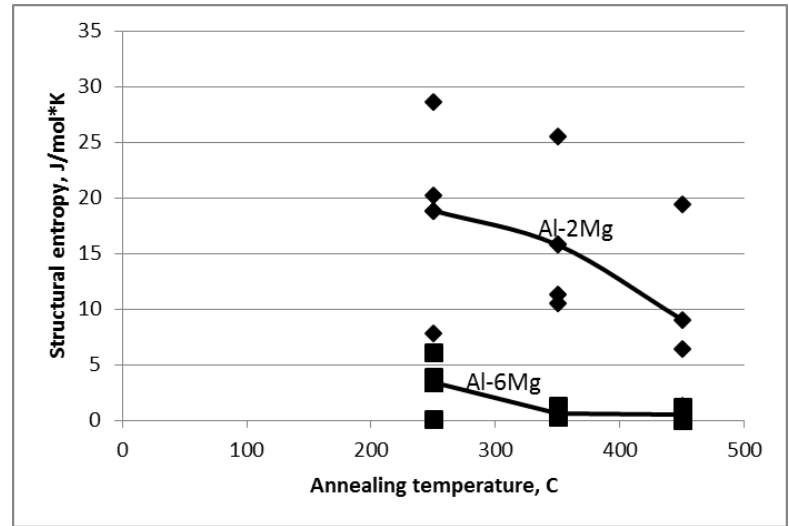

Fig. 6. The change in the structural entropy of samples from the alloys $\mathrm{Al}-2 \mathrm{Mg}(\downarrow)$ and $\mathrm{Al}-6 \mathrm{Mg}(\mathbf{m})$ after annealing at temperatures

From fig.6, that with annealing temperature increasing, the values of structural entropy decrease in both alloys. In the alloy $\mathrm{Al}-6 \mathrm{Mg}$, this change is more pronounced than in the $\mathrm{Al}-2 \mathrm{Mg}$ alloy. If we adhere to the principle of the system' minimum energy [14], according to which a spontaneous process is aimed to the system energy reducing, then a decrease in the value of the structural entropy taken in modulus means the flow of a spontaneous process.

Paper [13] shows the alloy A10.3CoCrFeMnNi treatment effect on grain size and strain curves behavior. The authors associate a strength increase with the grains of nanoscale size appearance in the process of grinding and electrospark sintering.

Results of research [16] show the appearance of a finely dispersed structure in cast annealed samples by reducing the structure ordering at the initial stage of annealing. However, the initial large grains with a BCC structure remained without signs of lattice rotation, recrystallization or grain regeneration during annealing.

In work [17] the deformation behavior of three aluminum alloys of composition AlxCoCrFeNi with high entropy was investigated. One alloy had a face-centered cubic structure $(\mathrm{x} \leq 0.3)$, in the second alloy the structure consisted of two phases (ordered (B2) and disordered $\mathrm{BCC}$ phase $(\mathrm{x} \leq 0.85)$, and the third alloy contained a mixture of all three phases $(x \leq 0,6)$. The deformational behavior studied by mechanical tests, scanning electron microscopy, and transmission electron microscopy showed a correlation between the dislocation density, the applied stress and compression deformation, which coincides with the behavior of austenitic stainless steel. For alloy with a high concentration of aluminum was observed an extremely high yield strength.

\section{Conclusions}

1. An increase in the annealing temperature of sheet specimens from $\mathrm{Al}-2 \mathrm{Mg}$ and $\mathrm{Al}-$ $6 \mathrm{Mg}$ alloys leads to an increase in grain size. The Al-6Mg alloy has a finer-grained structure than the $\mathrm{Al}-2 \mathrm{Mg}$ alloy. The difference in grain size increases with the annealing temperature.

2. The grain structure ununiformity decreases with annealing temperature increasing in both alloys in the temperature range $250 \ldots 350^{\circ} \mathrm{C}$. After annealing at a temperature of $450^{\circ} \mathrm{C}$, the grain structure ununiformity increases.

3. Structural entropy in both alloys decreases if the annealing temperature increases. The initial level of the configuration entropy, calculated from the chemical composition of the alloys, has higher values for the alloy with higher magnesium content. But the change in 
structural entropy is higher for an alloy with lower magnesium content. Also, the change in structural entropy with increasing annealing temperature is more pronounced in the $\mathrm{Al}-2 \mathrm{Mg}$ alloy than in the Al-6Mg alloy.

Financial support of the research was provided under State Agreement \#14.578.21.0228 of Ministry of Education and Science of the Russian Federation (unique identifier of the work (project) RFMEFI57817X0228).

\section{References}

1. Y. Shon, Sameehan S. Joshi, S. Katakam, R. S. Rajamure: Materials Letters 142 (2015)

2. D.B. Miracle, O.N. Senkov: Acta Materialia 122 (2017)

3. X. Fu, C. A. Schuh, E. A. Olivetti Scripta Materialia 138 (2017)

4. Y. Wang, Y. Yang, H. Yang, M. Zhang, S. Ma, J. Qiao: Materials Chemistry and Physics 210 (2018)

5. C. Ni, Y. Shi, J. Liu, G. Huang: Optics and Laser Technology 105 (2018)

6. N.Yu. Yurchenkoa, N.D. Stepanova, S.V. Zherebtsova, M.A. Tikhonovskyb, G.A. Salishchev: Materials Science \& Engineering A 704 (2017)

7. G.M. Karthika, S. Panikarb, G.D. J. Rama, R. S. Kottada: Materials Science \& Engineering A 679 (2017)

8. X. Qiu: Journal of Alloys and Compounds 735 (2018)

9. K. K. Alanemea, M. O. Bodunrina, S. R. Oke: Journal of Materials Research and Technology 5(4) (2016)

10. K. P. Kumar, M. G. Krishna, J. B. Rao: Bhargava Journal of Alloys and Compounds 640 (2015)

11. C.Y. Chenga, Y.C. Yanga, Y. Z. Zhonga, Y. Y. Chenb, T. Hsua, J. W. Yeh: Current Opinion in Solid State and Materials Science 21 (2017)

12. J. Moon, J. W. Bae, M. J. Jang, S. M. Baek, D. Yim, B. J. Lee , H. S. Kim: Materials Chemistry and Physics 210 (2018)

13. R. M. Pohan, B. Gwalani, J. Lee, T. Alam, J.Y. Hwang, H. J. Ryu, R. Banerjee, S. Hyung Hong: Materials Chemistry and Physics 210 (2018)

14. N.G. Kolbasnikov: Publishing house of the St. Petersburg Polytechnic University (2004)

15. I. L. Rogelberg, E. S. Shpichinetsky: Literature publishing on ferrous and non-ferrous metallurgy (1950)

16. K. S. Lee, J. H. Kang, K. R. Lim, Y. S. Na: Materials Characterization 132 (2017)

17. J. Joseph, N. Stanford, P. Hodgson, D. M. Fabijani: Journal of Alloys and Compounds 726 (2017) 